Polish Journal of Microbiology

2011, Vol. 60, No 2, 119-123

ORGINAL PAPER

\title{
Efficacy of UV Treatment in the Management of Bacterial Adhesion on Hard Surfaces
}

\author{
A. KOLAPPAN and S. SATHEESH ${ }^{\star}$ \\ Centre for Marine Science and Technology, Manonmaniam Sundaranar University, \\ Rajakamangalam Tamil Nadu, India
}

Received 8 May 2010, revised 22 December 2010, accepted 8 January 2011

Abstract

The efficacy of UV treatment to control bacterial adhesion onto hard surfaces was investigated in laboratory conditions. The major characteristics necessary for biofilm formation like extracellular polymeric substance (EPS) production, carbohydrate and protein concentration in EPS, and adhesion ability onto hard surface were studied using two bacterial strains isolated from marine biofilms. The results showed that there was a considerable difference between the control and UV treated bacterial cultures in their viability, production of EPS, and adhesion ability. The protein and carbohydrate concentration of the EPS and the adhesion of bacterial cells to surface were also considerably reduced due to UV treatment. This study indicates that treatment of water with UV light may be used to control biofilm development on hard surfaces.

Key words: biofilm, adhesion, antifouling, extracellular polymeric substance (EPS)

\section{Introduction}

Biofouling is a major problem for maritime operations such as shipping, off shore oil mining, coastal power generation, marine electronics, mariculture, marine construction or naval operations (Armstrong et al., 2000). Generally, industries like coastal power plants and desalination plants face biofouling problem due to the microbial growth and other higher organisms. The most common biofouling control method in industrial cooling water systems is chlorination (Yebra et al., 2004). However there is an increasing pressure to reduce or eliminate the use of chlorine due to the production of by-products. The use of chemo-biocides to control biofouling forms the major contaminant of marine environment. The chemical antifouling agents applied on the industrial objects, kill not only the foulers, but also have negative effect on other benthic community (Fingerman, 1988). The hazards of heavy metals in marine environment include their high toxicity, circulation in food chain and bioaccumulation.

The biofouling process involves various steps, from the initial conditioning of the surface by organic and inorganic molecules to the colonization by microorganisms and leading to the establishment of biofilm. There has been a growing interest in biofilms due to their significance in environmental, industrial and medical areas.
Since, biofilm formation on technical objects submerged in aquatic environments is a major problem with huge economic loss, there is a need to formulate adequate ecofriendly control measures. Flemming (1991) suggested that UV and ultrasound waves would be a potential source to minimize biofouling in industrial units. There are also reports on the inhibitory effect of UV on macrofouling organisms and is also effective in cleaning previous fouled surfaces (Zelver et al., 1981). UV radiation does not lead to any large-scale accumulation of toxic by-products in the ecosystem. Ultraviolet light is an established and increasingly popular alternative to chemicals for the disinfection of drinking water, wastewater, and industrial waters of various qualities. Ultraviolet radiation (10-400 nm wavelength) is of special interest because it is used in certain environments (e.g. hospital operating rooms) to kill microorganisms. Ultraviolet light is that portion of the electromagnetic spectrum that lies between X-rays and visible light. Four regions of the UV spectrum have been defined - vacuum UV between 100 and $200 \mathrm{~nm}, \mathrm{UV}-\mathrm{C}$ between 200 and $280 \mathrm{~nm}$, UV-B between 280 and $315 \mathrm{~nm}$, and UV-A between 315 and $400 \mathrm{~nm}$. Practical application of UV disinfection relies on the germicidal ability of UV-C and UV-B.

The effect of UV light on the microbial community is widely studied by various investigators (Chang et al., 1985; Harris et al., 1987). The efficiency of UV treatment

\footnotetext{
* Corresponding author: S. Satheesh, Centre for Marine Science and Technology, Manonmaniam Sundaranar University, Marina campus, Pannaiyoor, Rajakamangalam-629502, Kanyakumari District, Tamil Nadu, India; e-mail: satheesh_s2005@yahoo.co.in
} 
to control the biofilm formation and biofouling community development was studied by Munshi et al. (1999; 2001; 2005), Sharrer et al. (2007) and Wenjun and Wenjun (2009). However, there is a lack of information on the response of bacterial community to UV treatment, particularly the biofilm forming characteristics like EPS production and adhesion ability. There is also a scarcity of information on the effectiveness of the UV irradiation of incoming water for preventing microorganisms depositing on the surface. Hence, in the present study, an attempt has been made to evaluate the efficacy of UV treatment to control biofilm formation. The main objective was to investigate the effect of UV light on the EPS production and adhesion ability of marine bacteria involved in biofilm formation.

\section{Experimental}

\section{Materials and Methods}

Biofilm development assay. Two bacterial cultures, Alteromonas sp. (SS03) and Pseudomonas sp. (SS04) maintained in our laboratory were used for the present study. These bacteria were originally isolated from the marine biofilm developed on hard surfaces and tentatively identified based on the biochemical characteristics. A loop full of pure culture from the slant was inoculated into $100 \mathrm{ml}$ Zobell marine broth taken in $250 \mathrm{ml}$ conical flasks. The flasks were incubated for $24 \mathrm{~h}$ at room temperature. An aliquot of the broth was taken on microscopic slides to enumerate the number of bacterial cells present in per millilitre of the broth.

$500 \mathrm{ml}$ glass beakers were filled with $300 \mathrm{ml}$ sterile seawater (Millipore filtered and autoclaved) and $10 \mathrm{ml}$ of bacterial culture (approx. $10^{6}$ cells $\mathrm{ml}^{-1}$ ) was added. This bacterial culture introduced into seawater medium was exposed to UV light for 10 minutes (UV-C, TUV $30 \mathrm{~W} / \mathrm{G} 30$ ) in a laminar airflow chamber. The distance between the beakers with seawater medium and UV lamb was maintained at $15 \mathrm{~cm}$. After UV light treatment, the beakers were covered with parafilm and transferred into a sterile chamber. Experimental set-ups prepared as above without UV treatment were considered as controls. Five glass slides $(7.5 \times 2.5 \mathrm{~cm})$ were placed inside the beakers in slanting position as a substratum for biofilm development. The slides were removed from the beaker after 1, 2, 3, 4 and 5 hours of immersion. The slides were then air-dried, heat fixed and stained with methylene blue. The number of bacteria adhered to the slides were counted under a binocular microscope. The experiment was replicated $(\mathrm{N}=6)$ and the mean values were taken. One-way ANOVA (analysis of variance) was used to evaluate the effect of ultraviolet treatment on the adhesion of bacteria on hard surface.
Alternatively, separate experiments were carried out to assess the viability of bacterial cells in the biofilms. For this, the glass coupons were incubated in the bacterial culture introduced medium (UV treated and control) for 24 hours at room temperature. After incubation, the coupons were removed from the beaker and rinsed with sterile seawater to remove the unattached organisms. The biofilm developed on the coupon was scrapped off using a sterile nylon brush (each coupon was analysed separately) and dispersed in to $1 \mathrm{ml}$ sterile seawater (Millipore filtered and autoclaved). This biofilm sample was used for the isolation of extracellular polymeric substance and to assess the viability of bacterial cells.

Viable cell counts. In order to enumerate viable counts of bacterial population in both UV treated and control cultures, an aliquot of the biofilm sample isolated from the coupons was serially diluted using sterile seawater. The appropriate dilutions were spread on Zobell marine agar plates. The plates $(n=3)$ were incubated at room temperature for 24 hours, and colonies were counted manually.

Estimation of extracellular polymeric substance (EPS). The amount of EPS produced by the bacteria isolated from the both UV treated and control experimental set-up was analysed by estimating the total carbohydrate and protein concentration. For this, $5 \mathrm{ml}$ of the biofilm sample obtained as above was centrifuged at $10,000 \mathrm{~g}$ for $10 \mathrm{~min}$ at $4^{\circ} \mathrm{C}$. The cell pellets was discarded and the supernatant was mixed with equal amount of cold absolute ethanol. The precipitated EPS was diluted to known volume with distilled water and stored at $4^{\circ} \mathrm{C}$. Carbohydrate was estimated by Phenol Sulphuric acid method using glucose as standard (Dubois, 1956). The total protein content of EPS produced by the cultures was estimated by the Lowry et al. (1951) method, using Bovine serum albumin as the standard.

Characterization of EPS by thin-layer chromatography. The EPS isolated from the UV treated and control experiments was characterized by thin-layer chromatography (TLC). The EPS was loaded on a silica gel plate. n-butanol, acetic acid and distilled water (2:1:1) were used as the solvent system for TLC. Iodine crystals were used for the visualization of spots in the TLC plate.

\section{Results}

The number of Alteromonas sp. cells adhered on the coupons submerged in control medium was $3140 \mathrm{~cm}^{-2}$ (after 1 hour). The number of cells attached on the coupons submerged in UV treated medium was $1364 \mathrm{~cm}^{-2}$ after 1 hour. After five hours, the number of bacteria adhered on the coupons submerged in control medium was 8291 cells $\mathrm{cm}^{-2}$. The coupons submerged in UV treated medium showed a density of 1451 cells $\mathrm{cm}^{-2}$ 


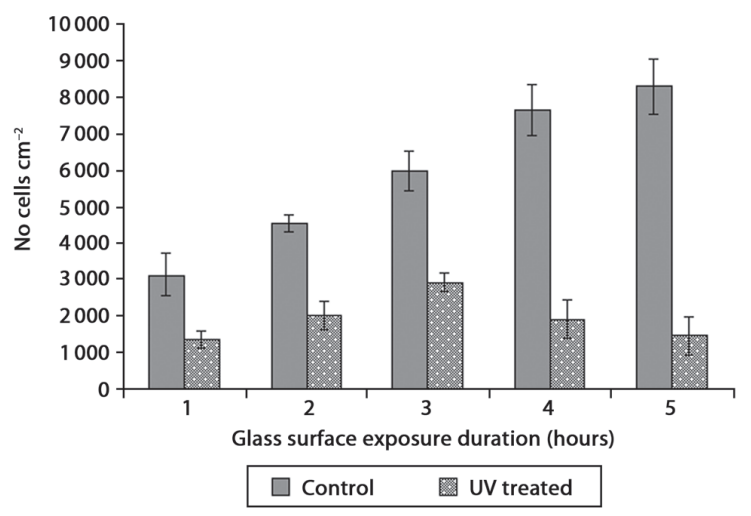

Fig. 1. Adhesion of UV treated and control Alteromonas sp. cells on glass slides.

after 5 hours of exposure (Fig. 1). The cell attachment assay revealed that the number of Alteromonas sp. adhered to glass surface was reduced significantly after treated with UV (one-way ANOVA, $F=16.16$; d.f $=1$, 9; $P<0.05)$.

Similarly, the biofilm adhesion assay with Pseudomonas sp. showed considerable variations between control and ultraviolet treated cultures (Fig. 2). After one hour of glass surface exposure 2033 cells cm$~^{-2}$ were observed in the control medium. The number of cells adhered on the coupons submerged in the UV treated medium was 1160 cells $\mathrm{cm}^{-2}$. At the end of the exposure period, 9233 cells cm$~^{-2}$ were observed in the control and 2395 cells $\mathrm{cm}^{-2}$ on the coupons immersed in UV treated medium. One-way ANOVA showed that the adhesion of Pseudomonas sp. to glass surface did not differ significantly between the coupons submerged in UV treated and control medium $(F=3.49$; d.f $=1,9 ; P>0.05)$.

The carbohydrate concentration of EPS of the Alteromonas sp. biofilm isolated from the coupons submerged in UV treated medium was $5.44 \mathrm{mg} \mathrm{ml}^{-1}$. The EPS of the Alteromonas sp. biofilm isolated from the coupons submerged in control medium was $7.34 \mathrm{mg} \mathrm{ml}^{-1}$ (Table I). The carbohydrate concentration of the EPS of Pseudomonas sp. isolated from the control medium coupons was $3.37 \mathrm{mg} \mathrm{ml}^{-1}$ and the coupons submerged in UV treated medium showed a value of $1.26 \mathrm{mg} \mathrm{ml}^{-1}$.

The protein concentration of the EPS produced by Alteromonas sp. from the UV treated medium was $4.01 \mathrm{mg} \mathrm{ml}^{-1}$ and in the control, the protein concentra-

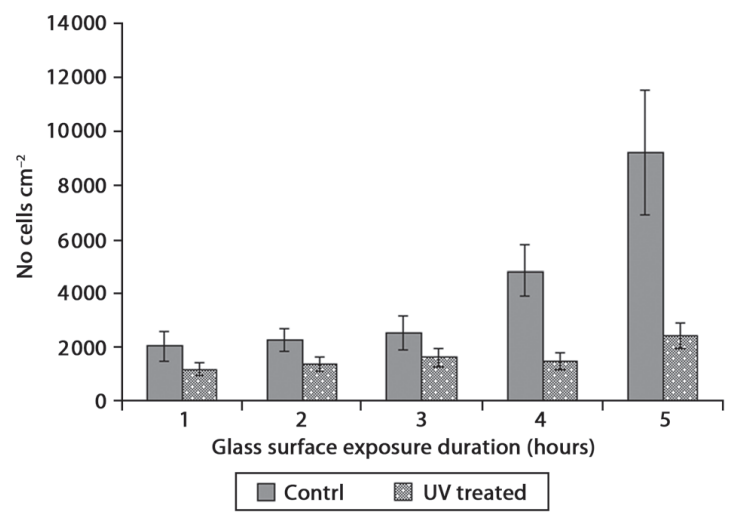

Fig. 2. Adhesion of UV treated and control Pseudomonas sp. cells on glass slides.

tion was $5.23 \mathrm{mg} \mathrm{ml}^{-1}$ (Table I). The protein concentration of EPS synthesized by the Pseudomonas sp. isolated from the coupons submerged in UV treated medium was $8.62 \mathrm{mg} \mathrm{ml}^{-1}$ and in the control, the concentration was $9.48 \mathrm{mg} \mathrm{ml}^{-1}$. In general, results showed that the total protein concentration of the EPS was not reduced much due to the UV treatment.

The EPS synthesized by the bacteria adhered to coupons submerged in both UV treated and untreated systems were subjected to thin-layer chromatography to understand the changes in the carbohydrate composition of the EPS. Results revealed that the carbohydrate composition of EPS was considerably changed due to UV treatment. The EPS synthesized by Alteromonas sp. adhered to coupons submerged in control medium showed three distinct spots on the thin layer chromatogram. The EPS isolated from the Alteromonas sp. adhered on the coupons submerged in the UV treated medium showed two spots. Further, the EPS of the Alteromonas $\mathrm{sp}$. isolated from the coupons submerged in control and UV treated systems did not show any similarity in the RF values. Rf values of the EPS produced by the Alteromonas sp. control culture were $0.196,0.312$ and $0.651 \mathrm{~cm}$. In UV treated Alteromonas culture, the $\mathrm{Rf}$ values were 0.16 and $0.607 \mathrm{~cm}$. The EPS synthesized by the Pseudomonas sp. isolated from the coupons submerged in control medium also showed three spots and the bacteria isolated from the coupons submerged in UV treated medium showed only one spot (Fig. 3). The Rf values of the spots exhibited by the EPS of

Table I

Effect of UV treatment on the carbohydrate and protein concentration (mean \pm standard deviation) of extracellular polymeric substance (EPS) synthesized by bacteria

\begin{tabular}{|l|cc|c|c|}
\hline \multirow{2}{*}{ Bacterial species } & \multicolumn{2}{|c|}{ Protein $\left(\mathrm{mg} \mathrm{ml}^{-1}\right)$} & \multicolumn{2}{c|}{ Carbohydrate $\left(\mathrm{mg} \mathrm{ml}^{-1}\right)$} \\
\cline { 2 - 5 } & Control & UV treated & Control & UV treated \\
\hline Alteromonas sp. & $7.34 \pm 0.84$ & $5.44 \pm 0.48$ & $5.23 \pm 0.799$ & $4.01 \pm 0.97$ \\
\hline Pseudomonas sp. & $3.379 \pm 0.14$ & $1.26 \pm 0.113$ & $9.48 \pm 1.72$ & $8.62 \pm 2.14$ \\
\hline
\end{tabular}




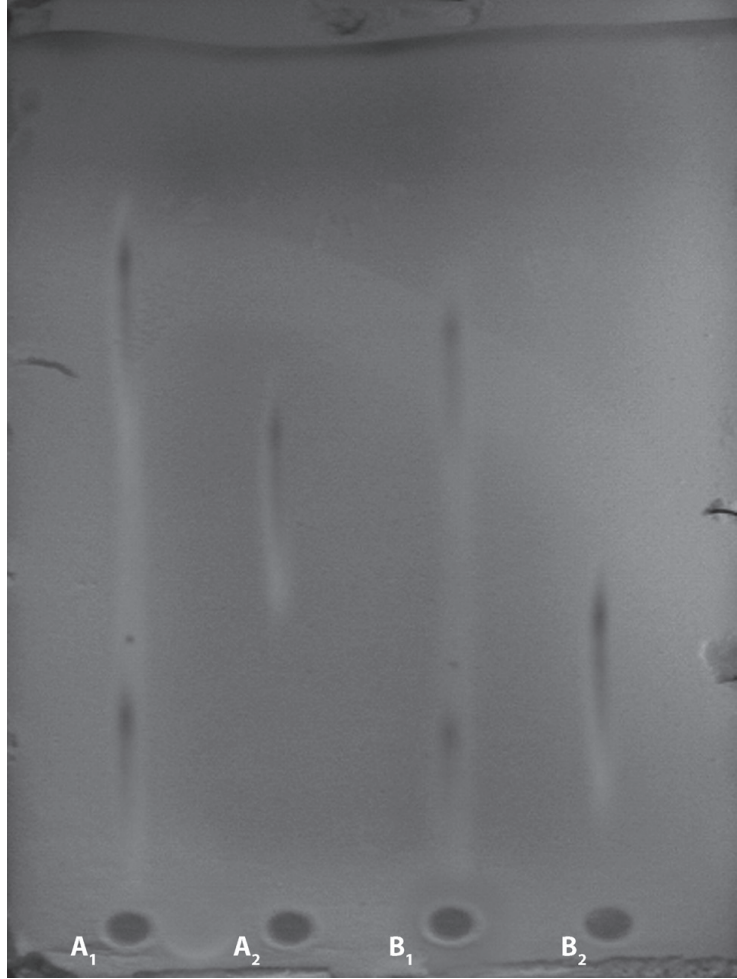

Fig. 3. Thin-layer chromatogram of the extracellular polymeric substance isolated from both UV treated and control bacterial cells. A - Alteromonas sp. ( $\mathrm{A}_{1}$ - Control, $\mathrm{A}_{2}$ - UV treated) B - Pseudomonas sp. $\left(\mathrm{B}_{1}-\right.$ Control, $\mathrm{B}_{2}-\mathrm{UV}$ treated)

Pseudomonas sp. isolated from the control medium coupons were $0.165,0.247$ and $0.661 \mathrm{~cm}$. The Rf value of Pseudomonas sp. isolated from the UV treated medium coupons was $0.454 \mathrm{~cm}$.

The viable counts of biofilm sample isolated from the UV treated and the control medium were also varied. The viable count of Alteromonas sp. isolated from the coupons submerged in UV treated medium was $4.5 \pm 1.8 \times 10^{5} \mathrm{CFU} \mathrm{m}{ }^{-1}$. The viability of Alteromonas $\mathrm{sp}$. isolated from the control medium coupons was $38.5 \pm$ $9.3 \times 10^{5} \mathrm{CFU} \mathrm{ml}^{-1}$. The viable count of Pseudomonas sp. biofilm sample isolated from the coupons submerged in the control medium was $34.25 \pm 11.4 \times 10^{5} \mathrm{CFU} \mathrm{ml}^{-1}$. The biofilm sample of coupons submerged in UV treated medium showed a viability of $11.25 \pm 3.71 \times 10^{5} \mathrm{CFU} \mathrm{m} l^{-1}$. In general, the viability of bacterial cultures was reduced after UV treatment.

\section{Discussion}

The development of biofilm and fouling communities is a multiple event with numerous interactions taking place between fouling organisms colonizing the surface. The first colonizers on any newly exposed surface in marine waters are bacteria and they have been found to affect the subsequent recruitment of both microorganisms and macrofoulers. Hence, control of biofilms on surfaces is an important strategy in any biofouling management programme. The results of the present study indicate that the viability of the bacterial cultures treated with UV light was reduced considerably. Previous studies by Munshi et al. (2005) also reported a reduction in bacterial load after UV treatment from a desalination plant. Generally, sensitivity of microorganisms to UV radiation may vary with species (Gaudy and Gaudy 1980). In the present study, Alteromonas sp. showed lower viability after UV treatment than that of Pseudomonas sp.

The adhesion of bacteria to glass surface was reduced considerably on the coupons submerged in UV treated medium. This may be due to the change in cell surface properties after UV treatment. Previous studies by Li and Logan (2005) reported a $40 \%$ reduction in the adhesion of Bacillus subtilis cells to the hard surface. They also reported that UV treatment oxidizes the surface polymers of the bacteria and decreases their adhesion to surface. The active attachment of bacterial cells is facilitated by the cell surface by the cell surface properties such as adhesion proteins, capsules, surface charge, flagella and pili (Kumar and Anand 1998). Any change in the cell surface properties influences adhesion of the cells to the solid surfaces. Primary effect of UV light on bacterial adhesion was to reduce the hydrophobicity of the bacterial cell surface. The hydrophobicity of the cell surface is important in adhesion because hydrophobic interactions tent to increase with an increasing nonpolar nature of one or both surfaces involved (i.e., the microbial cell surface and the substratum).

Microorganisms are inactivated by UV light as a result of photochemical damage to their nucleic acids (Sonntag and Schuchmann, 1992). Absorbed UV promotes the formation of bonds between adjacent nucleotides, creating double molecules or dimmers (Jagger, 1967). While the formation of thymine - thymine dimmers are the most common, cytosine - cytosine, cytosine-thymine, and uracil dimerization will also occur. Formation of a sufficient number of dimers within a microbe prevents it from replicating the DNA and RNA.

The amount of carbohydrate and protein in the EPS synthesized by the bacteria isolated from the coupons submerged in the UV treated medium was lesser than that of the control. This indicated that the extracellular polymeric substance production was affected due to the UV treatment. Most of the fouling organisms including bacteria use adhesive materials with permanent or temporary adhesive capabilities to attach to surfaces (Callow and Callow, 2002). Extracellular polymeric substances are considered as adhesive material involved in the process of biofilm formation (Flemming et al., 
2000). The EPS consists of polysaccharides, polyuronic acids, proteins, nucleic acids and lipids (Decho, 1990; Schmidt and Ahring, 1994). EPS may account for 50-90\% of the total organic carbon of biofilms (Flemming et al., 2000) and can be considered as the primary matrix material of the biofilm. The EPS also bridge the microbial cells with the substratum and permit negatively charged bacteria to adhere both negatively and positively charged surfaces. Hence, the reduction in EPS production may be one of the possible reasons for the low abundance of bacteria on the coupons submerged in UV treated medium.

The efficiency of UV on the removal of well-established biofilm matrix has some practical constraints. Flemming (1991) indicated that the effectiveness of UV treatment for removing an established biofilm might be low due to entrapped particles within the biofilm. Hence, in the present study, the effect of UV irradiation of the incoming water to control biofilm was analysed. The results of the present study suggest that UV light is a promising source for the control of bacterial fouling. There are large amounts of experience and data available on its use for medical sterilization. The UV may be effective in control biofilm especially in cooling systems if the incoming water is irradiated using specific UV devices. More studies on this aspect will certainly improve our understanding on the role of UV light in biofouling control.

\section{Literature}

Armstrong E., K.G. Boyd, A. Pisacane, C.J. Peppiatt, and J.G. Burgess. 2000. Marine microbial natural products in antifouling coatings. Biofouling 16: 215-224.

Callow M.E. and J.A. Callow. 2002. Marine biofouling: a sticky problem. Biologist 49: 1-5.

Chang J.C.H., S.F. Ossoff, D.C. Lobe, M.H. Dorfman, C.M. Dumais, R.G. Dualls and J.D. Johnson. 1985. UV inactivation of pathogenic and indicator microorganisms. Appl. Environ Microbiol. 49: 1361-1365

Decho A.W. 1990. Microbial expolymer secretions in ocean environments: their role in food webs and marine processes. Oceanogr. Mar. Biol. Ann. Rev. 28: 73-153.

Dubois M. 1956. Colorimetric method for determination of sugars and related substances. Anal.Chem.28: 50-356.

Fingerman S.W. 1988. Environmental pollution by heavy metals from antifouling compounds. pp. 781-789. In: Thompson M.F, R. Sarojini and R. Nagabhushanam (eds). Marine Biodeterioration: Advanced techniques applicable to the Indian Ocean. Oxford \& IBH, New Delhi. Flemming H.C. 1991. Biofouling: effects and control. pp. 47-81 In: Flemming H.C and G. Gregory (eds). Biofouling in Industrial Water Systems. Springer Publisher, New York.
Flemming H.C., J. Wingender, C. Griegbe and C. Mayer. 2000. Physico-chemical properties of biofilms. Pp. 19-34. In: Evans L.V. (ed). Biofilms: recent advances in their study and control. Harwood Academic Publishers, Amsterdam.

Gaudy A.F and E.T. Gaudy. 1980. Microbiology for Environmental scientists and Engineers. Mc Garw Hill book co. New York.

Harris G.D., V.D. Adams, D.L. Sorensen and M.S. Curtis. 1987.

Ultraviolet inactivation of selected bacteria and virus with photoreactivation of the bacteria. Water Res. 21: 687-692

Jagger J. 1967. Introduction to research in ultraviolet photobiology. Englewood Cliffs, New Jersey: Prentice-Hall.

Jain A., K.K. Nishad, K.K. Narayan, B. Bhosle. 2007. Effects of DNP on the cell surface properties of marine bacteria and its implication for adhesion to surfaces. Biofouling 23: 171-177.

Kumar C.G and S.K. Anand. 1998. Significance of microbial biofilms in food industry. Int. J. Food Microbiol. 42: 9-27.

Li B. and B.E. Logan. 2005. The impact of ultraviolet light on bacterial adhesion to glass and metal oxide-coated surface. Colloid surface B. 41: 153-161.

Lowry O., H. Roseburg, A. Farr and R. Randwall. 1951. Protein Measurement with the Folin-Phenol reagent. J. Biol.Chem. 193: 265-275.

Munshi H.A., N. Sasikumar, A.T. Jamaluddin and K. Mohammed. 1999. Evaluation of ultra-violet radiation disinfection on the bacterial growth in the SWRO pilot plant Al-Jubail, seawater. pp. 603-618. In: Proceedings of the fourth Gulf water conference, 13-18 February 1999, Bahrain. Water science and Technology Association, Manama, Bahrain.

Munshi H.A., O.M. Saeed, T.N. Green, A.A. Al-Hamza, M. Farooque and A.R.A. Ismail. 2001. Application of ultraviolet radiation to control bacterial growth in the RO feed water from nanofiltration membranes. Technical Report: TR: APP 3805/9001, Saline water conversion corporation, Saudi Arabia.

Munshi H.A., O.M. Saeed, T.N. Green, A.A. Al-Hamza, M. Farooque and A.R.A. Ismail. 2005. Impact of UV radiation on controlling biofouling problems in NF SWRO desalination process. In: International Desalination Association (IDA) world congress, Singapore.

Schmidt J.E. and B.K. Ahring, 1994. Extracellular polmers in granular sludge from difference up flow anaerobic sludge blanket (UASB) reactors. Appl. Microbiol. Biotechnol. 42: 457-462

Sharrer M.J. and S.T. Summerfelt. 2007. Ozonation followed by ultraviolet irradiation provides attractive bacteria inactivation in a freshwater recirculating system. Aquat. Eng. 37: 180-191.

Sonntag C.V. and H.P. Schuchmann. 1992. UV disinfection of drinking water and by-product formation-some basic considerations. J. Water SRT Aqua. 41: 67-74.

Sutherland I.W. 2001. Biofilm exopolysaccharides: A story and sticky frame work. Microbiology, 147: 3-9.

Wenjun S. and L. Wenjun. 2009. Impact of the ultraviolet disinfection process on biofilm control in a model drinking water distribution system. Environ. Engi. Sci. 26:809

Yebra D.M., S. Kiil and K. Dam-Johansen. 2004. Antifouling technology-past, present and future steps towards efficient and environmentally friendly antifouling coatings. Prog. Org. Coat. 50: 75-104.

Zelver N., R. Legan and W.G. Charaklis. 1981. Biofouling control with UV/peroxide. A laboratory study. Pp. 1164-1183. In: Proceedings of the water reuse symposium II Washington D.C. 